\title{
An Examination of the Implementation of Existing Policies on Renewable Energy in Nigeria: How Effective?
}

\author{
Sunny Gavin Daudu, Stella 0. Idehen \\ Faculty of Law, Benson Idahosa University, Benin, Nigeria \\ Email: dasunoikao@yahoo.co.uk, sidehen@biu.edu.ng
}

How to cite this paper: Daudu, S.G. and Idehen, S.O. (2021) An Examination of the Implementation of Existing Policies on Renewable Energy in Nigeria: How Effective? Journal of Power and Energy Engineering, 9, 104-119.

https://doi.org/10.4236/jpee.2021.95007

Received: February 4, 2021

Accepted: May 25, 2021

Published: May 28, 2021

Copyright $\odot 2021$ by author(s) and Scientific Research Publishing Inc. This work is licensed under the Creative Commons Attribution International License (CC BY 4.0).

http://creativecommons.org/licenses/by/4.0/

\begin{abstract}
Renewable energy utilisation is presently at its infancy in Nigeria despite its nation and global relevance. This paper attempts an examination of renewable energy policies aim of finding out how relevant and effective they have been in the Nigeria energy mix. Research shows that the implementations of these renewable policies are not fully effective as a result of several constraints, such as the lack of a supporting legislation, inadequate funding, and absence of a regulatory agency to oversee the development of renewable energy sources. Presently only policies exist for renewable energy in Nigeria. The absence of an effective legislation in renewable energy may hinder the efficient and full utilization of renewable energy in Nigeria. This paper argues for the enactment of an enabling renewable energy law as well as the establishment of a renewable energy agency saddled enforcement of the law, so as to hasten the rapid development and growth of renewable energy utilisation in Nigeria.
\end{abstract}

\section{Keywords}

Renewable, Energy, Policies, Legislation

\section{Introduction}

With respect to energy production in Nigeria, concentration for the past one hundred years (100) has majorly focused on fossil fuel which is primarily oil, gas and coal [1]. A cursory look at legislations in the energy sector shows that laws are made in respect of the oil, gas and coal sector but there are no specific laws for renewable energy development and utilization despite the fact that Nigeria enjoys an abundance of enormous natural resources which include renewable 
energy sources such as solar, hydropower, wind, biomass and which are easily replenishable, do not deplete easily and are clean and which are more beneficial to the environment because they are friendly [2]. Energy utilization is almost totally dependent on fossil fuel as almost all sectors of the economy are dominated by oil and gas consumption. This has made Nigeria be a contributor to environmentally damaging activities in the increase of its global share of greenhouse gas (GHG) emissions [3]. Research shows that renewable energy that can serve as alternative has a relatively short history in terms of energy dependency and utilization. With the various environmental problems associated with the utilization of fossil fuel, it becomes imperative for government to explore alternative energy resources, which renewable energy offers. The necessity of this paper is to advocate the fact that renewable energy is more environmentally friendly and would contribute to reducing greenhouse gases (GHGs).

The past two decades have seen some efforts made by the Nigerian government in developing renewable energy by the creation of policies. For instance, the National Energy Policy 2003 (NEP) provides for both fossil fuels and renewable energy while the Renewable Energy Master Plan 2005 (REMP) which is drawn from NEP focuses mainly on renewable energy. The paper shall examine these policies with a view to advocating the necessity for an effective energy mix in Nigeria. An assessment of the success and the challenges that hamper the effective implementation of these policies shall be carried out. The paper will proffer recommendations to ensure that an enabling law and an agency are enacted to cater for its effective implementation.

\section{Evolution of Renewable Energy in Nigeria}

Renewable energy is a concept that has evolved as a result of the need for environmentally friendly options to fossil fuels for the production of energy to meet various needs. Over the years, energy consumption has mainly relied on fossil fuels. The consumption and production of energy especially oil and gas is reported to be responsible for major disasters like acid rain, pollution of oceans, depletion of the ozone layer, local atmospheric air pollution and climate change [4]. The reliance and utilization of fossil fuels has led to the underdevelopment of renewable energy and has severely limited access to energy consumption by Nigerians.

\section{Examination of Policies with Respect to Renewable Energy}

\subsection{National Energy Policy 2003 (NEP) [5]}

In 2003, the Federal Government of Nigeria approved renewable energy as part of its national energy policy with the aim of articulating sustainable exploitation and utilisation of all viable energy resources [6]. The objective of the Policy is among other things to ensure the development of the nation's energy resources with diversified energy resources option for the achievement of national energy security and an efficient energy delivery system with an optimal energy resource 
mix based on the principle of an energy economy in which modern renewable energy increases its share of energy consumed and provides affordable access to energy throughout Nigeria [7].

Some of the key elements addressed in the Policy are to develop, promote and harness the renewable energy resources of the country and incorporate all the viable ones into the national energy mix, to promote decentralised energy supply especially in rural areas, based on renewable energy resources, to de-emphasise and discourage the use of wood as fuel as it provides for de-emphasising fuel wood and promotes the use of renewable energy and other environmentally friendly technologies that serve as alternatives like smokeless briquettes, to promote efficient methods in the use of biomass energy resource and to keep abreast with international developments in renewable energy technologies and applications.

The Policy looked at the various sources of energy and drew policies, objectives and strategies on how to drive the policies and strategies for the respective energy sources including renewable energy and rural electrification and therefore constitutes a blue print for all subsequent policies on the promotion of renewable energy [8]. These policy provisions have provided the impetus for the Federal Ministry of Power and Steel to embark on the development of the National Policy Guideline for Renewable Electricity and Renewable Electricity Action Programme.

The Policy also created the platform upon which the rural electrification fund was later incorporated under the Rural Electrification Agency as well as constituting a blueprint for all subsequent policies on the promotion of renewable energy [8].

In 2013, the National Energy Policy was reviewed to reflect recent developments in the energy sector with emphasis on renewable energy and energy efficiency. In recognition of the importance of renewable energy, it has made provision for all forms of energy including renewable energy sources especially solar, wind and biomass and how they can be effectively utilised. It is reported that the Nigerian government has mandated electricity distribution companies in Nigeria to acquire a minimum percentage of electricity from renewable energy sources [8]. Though the Policy seeks to develop energy strategy to address growing energy demand with affordable sustainable services that would enhance socio-economic development [8], the issue that arises is how these lofty objectives can be made possible, without an enabling legislation to help propel the move towards renewable energy is one to be considered.

The overall thrust of the energy policy is the optimal utilisation of the nation's energy resources for sustainable development. It is noted that although the policy has led to the setting up of the Energy Commission of Nigeria and the various energy research centres in various universities [8], not much has been done in harnessing renewable resources to the extent that it can be relied upon for national utilisation and this has led to the policy being referred to as a toothless bull dog 
[9]. This paper agrees with the above statement in the sense that a policy in the true sense is restricted in terms of implementation as it does not have the capacity to enforce and ensure total compliance for the objectives to be attained.

\subsection{National Economic Empowerment and Development Strategy (NEEDS) $2004^{1}$}

The National Economic Empowerment and Development Strategy was drawn up by the National Planning Commission with the aim of meeting the development challenges of Nigeria. The essence of NEEDS is finding ways and means to alleviate poverty by involving the use of human resources and the available natural resources to produce goods to satisfy the economic needs of the community [10]. Its other goals include among others to consolidate the achievements of the previous legislative period with a view to creating a platform for further sustainable poverty reduction. NEEDS recognises and provides for the promotion of the increase in the share of the utilisation of the energy mix and stresses the need for a renewable energy agency to be created with its equipments put in place as well as making available provision for adequate funds for that purpose through the National Power Sector Reform Act. This recommendation has been commended as a milestone in respect of the adoption of renewable energy in the power sector [11].

\subsection{Electric Power Sector Reform Act 2005 (EPSRA) [12]}

The Electric Power Sector Act facilitated the end of the monopoly of Nigeria Electricity Power Authority and brought in liberalisation of the current independent and private status of the generation and distribution chains in the Nigerian Power Sector. The EPSRA which is a consequence of the National Electric Power Policy 2001 provides a new legal and regulatory framework for the energy sector. The Act lays out further guidelines for the licensing and regulation of all parts of the value chain of generation, transmission, distribution and supply of electricity and also provides for rules to ensure performance standards and uphold consumer rights and obligations [12]. It also provides for the promotion of electricity generated from all sources of energy including renewable energy by the creation and mandating National Electricity Regulatory Commission to create a level playing field in the Nigerian electricity market and coordinate the activities of the deregulated market [13].

The Act also provides for the Power Consumer Assistance Fund and Rural Electrification Fund. This has ensured the liberalisation of the Nigerian power sector and paved way for the privatization and unbundling of the sector. To emphasize the importance of the role of renewable energy, Part IX under Rural Electrification, Section 88(9) of the Act, provides that information shall be presented to the President by the Minister of Power and Steel Development on

${ }^{1}$ The Research Centres Are Ahmadu Bello University, University of Nigeria, Nsukka, Obafemi Awolowo University, Ile-Ife. 
matters which include among others, the following;

1) expansion of the mini grid;

2) development of isolated and mini grid systems;

3) renewable energy power generation;

4) establish a rural electrification agency to expand access to electricity which would include renewable energy to the rural areas and the financing of its activities.

The ultimate goal of the reformed Act is to increase efficiency, accessibility, reliability and affordability of quality electricity supply that would enhance and stimulate economic growth, development and transformation in the country [14]. It is noted that though the EPSRA is commendable in some quarters, it has not been able to push for renewable energy law to be put in place. It has been noted that despite the fact that the Act providing for renewable energy, renewable energy is listed among other energy sources which makes it difficult for the Act to place emphasis on renewable energy rather, the act still focuses more on oil and gas development and utilisation. It is canvassed that if a renewable energy Act is enacted, the Act would specifically provide the much needed attention and be effectively utilised to vigorously develop and canvass for the inclusion of renewable energy in the energy mix of the country [9]. The lack of legislation on renewable energy development and utilisation has however created a gap in the Nigerian quest for effective and efficient energy mix. It is our contention that the enactment of a specific legislation on renewable energy utilisation would act as a catalyst for foreign direct investment in the sector and this would reduce the over dependence on fossil fuel consumption in Nigeria.

\subsection{Renewable Electricity Policy Guidelines 2006 [15]}

The Renewable Electricity Policy Guidelines on Renewable Electricity (REPG) is the federal government overarching policy on all electricity derived from renewable energy sources. It sets out the Federal government's vision, policies and objectives and is a creation of the Federal Ministry of Power and Steel. The Guidelines stipulates that the Federal government would take steps to expand the market for renewable electricity to at least five percent of total electricity generation and a minimum of 5 TWh of electric power production by 2016. The Policy gives a brief overview of the electricity sector situation and recognises the advantages renewable energy can bring to the system like adding additional generation systems to the already constrained systems, enhancing the stability of electricity by mitigating local disruptions in supply and reduction of emissions. Renewable energy is regarded as a means to extend electricity services to those not yet connected to supply sources of electricity, especially in some rural areas, where inhabitants live without input or electricity supply. The REPG sets the following policy goals along with respective strategies which includes; expansion of the market for renewable electricity to at least five percent of total electricity generating capacity and a minimum of 5 TWh of electric power production, es- 
tablishment of stable and long-term favourable pricing mechanisms and ensuring of unhindered access to the grid with guaranteed purchase and transmission of all electricity produced by renewable electricity producers and obliging the grid operators upgrade the system accordingly, the construction of independent renewable electricity systems in areas not covered by the electricity grid., development of innovative, cost-effective and practical measures to accelerate access to electricity services in rural areas through renewable sources, setting up of a renewable electricity trust fund under the supervision of the rural electrification fund, creation of a multi-stakeholder partnership for the delivery of renewable electricity to meet national development goals and broadening international cooperation in expanding the role of renewable electricity for meeting national development goals which would contribute to global efforts in addressing climate change. It is important to note that the target set for year 2016 is yet to be achieved.

The use of renewable electricity has been a successful story in Germany where renewable energy is made a national priority. Renewable energy utilization also enjoys a legislation flavor in Germany no similar policy exists in Nigeria although the National Energy Policy advocates and encourages renewable energy sources but this is yet to translate to a national priority as the country presently grapples with epileptic power generation and supply [16].

\subsection{Renewable Electricity Action Programme (REAP) 2006 [17]}

To aid the actualisation of the REPG, the Renewable Electricity Action Programme was issued by the Federal Ministry of Power in 2006. The document sets out a roadmap to implement the Policy Guidelines. The programme gives an overview of the Nigerian electricity sector and relates it to renewable energy development by outlining the potentials, technologies and the potential market of renewable energy. The programme also elaborates on the development targets per technology and application, strategies for their achievement, outlines financing procedures through the Renewable Electricity Fund and other sources, looks into roles of government bodies and concludes with a risk assessment as well as structures for monitoring and evaluation.

The core focus of the programme is on utilising all forms of renewable energy sources for electricity generation and highlights potential gaps, technical assessments and financial implications, benefits and limitations of Nigeria's renewable energy sources potentials [18]. It appears that with the restructuring of the Ministry of Power and Steel to the Ministry of Power, the programme appears abandoned.

\subsection{National Biofuel Policy and Incentives 2007 [19]}

The Policy is aimed at formulating a bio fuel support programme which integrates the agricultural sector of the economy with the downstream petroleum sector. The Policy defines bio fuel as fuel ethanol, bio-diesel and other fuels 
made from biomass which are primarily used for automotive, thermal and power generation. This definition does not allow for external interpretation and can be commended for removing the problem of individualistic definitions.

The goal of this policy is the development and promotion of a national fuel ethanol industry utilising agricultural products and is in line with the Federal government directive on automotive biomass programme for Nigeria in 2005.

The Nigerian National Petroleum Corporation has been given the mandate to create an enabling environment for the takeoff of the ethanol industry. This Policy is aimed at the gradual reduction of the nation's dependence on fossil fuel while creating a commercially viable industry. The Policy outlines several benefits linked to bio fuels some of which are; environmental benefits in terms of reduction of emissions and ozone pollution.

\subsection{Nigeria Vision 20: 2020, 2010 [20]}

The Nigeria Vision 20: 2020 was birthed with the approval of the Federal Executive Council with the constitution of the National Council on NV20:20 in collaboration with the National Planning Commission [21]. The focal point of the document is a long term plan for stimulating Nigeria's economic growth and launching the country into a path of sustained and rapid socio-development. The document articulates Nigeria's economic growth and development strategies for an eleven year period from 2009 to 2020 and will be implemented using a series of medium term national development plans [21]. In drawing its objectives, it also encapsulates the key principles of the National Economic Empowerment and Development Strategy (NEEDS) and the Seven point Agenda.

Among the several issues, the Vision 20: 2020 strategic objective seeks to ensure that the power sector is able to efficiently deliver sustainable, adequate qualitative, reliable and affordable power in a deregulated market. To be able to deliver this, the document sets targets that will aid the implementation of its vision and these targets are to generate electricity from $6000 \mathrm{MW}$ in 2009 to 20,000 MW in 2015 and 35,000 MW in 2020 [8]. It further estimates that in the medium term, existing independent private partners will be encouraged to increase capacity and ongoing NIPP projects will be fast tracked to achieve the target of 20,000 MW by 2015 while incentives will be granted to new entrants particularly for renewable energy generation in order to achieve additional generation capacity. Between 2011 and 2020, it is estimated that the IPPS will generate an incremental 20,000 MW on an annual basis and it is also expected that in the long term, additional large hydro plants, coal-fired plants, IPPS and renewable power generating plants comprising of solar, hydro, and biomass will be installed to further increase power generation capacity to 35,000 MW.

It is submitted that though the vision effectively captures the aspirations of Nigerians, it has not been able to actualise the vision for 2009 and 2015 in terms of power generation, as generation is presently less than $6000 \mathrm{MW}$ and perhaps that is why the drafters called for this blueprint to be enacted into law [22]. 


\subsection{Renewable Energy Master Plan 2012 [23]}

The Renewable Energy Master Plan is a roadmap for the actualization of government's commitment to create the necessary enabling environment for sustainable energy supply for national development with active participation of the private sector. The Policy provides for programmes with targets, timelines and activities as well as incentives to promote the attainment of the programmes which would help grow the market. The Plan is implemented by the Federal Ministry of Environment that aims to increase the contribution of renewable energy to total energy consumption [23].

The first draft of the REMP which was initiated in 2005 was considered voluminous and therefore needed to be precise and concise thus the review in 2015. The objectives of the Policy are to among others enhance national energy security, expand access to energy especially in rural areas and improve learning, capacity building, research and development on various renewable energy technologies in the country and provide a roadmap for achieving a substantial share of the national energy supply mix through renewable energy.

The Policy notes that one of the main constraint stalling the rapid development and diffusion of technologies for the exploitation and utilisation of renewable energy resources are the absence of a market and the lack of appropriate policy, regulatory and institutional framework to stimulate demand and attract investors [23]. The policy further notes that the Federal Government as a result has formulated many renewable energy related policies into programmes with timelines of short term for 2013-2015, medium term for 2016-2020 and long term for 2021-2030.

The REMP also tabulates the various energy policies, regulations and institutional frameworks with expected activities and states the ministries responsible for overseeing the activities with timelines within which to fulfill the targets/timelines as well as provide for the development of financing options programs for instance producing a draft legislation for a fossil fuel levy act to finance renewable energy development projects in the country and the establishment of a renewable energy development fund. It is further stated that the Policy if fully implemented, will increase the contribution of renewable electricity to about $20 \%$ of the total electricity supply in the nation. The REMP suggests the review of policy, legal, institutional, fiscal and regulatory instruments as it envisions a nation driven by renewable energy and by the middle of the century, sustainable and affordable renewable energy that will provide half of the country's total energy demand.

\subsection{Renewable Energy Feed in Tariff (REFITS) 2016 [23]}

Section 76 of the Electric Power Sector Reform Act empowers the Nigerian Electricity Regulatory Commission to establish a methodology which determines electricity tariff in the Nigerian Electricity supply industry and issued the Multi Year Tariff Order (MYTO) which sets out tariffs for the generation, transmis- 
sion and distribution of electricity [24]. In recognition of the importance of renewable energy, the Renewable Energy Research and Development Division of the Nigerian Electricity Regulatory Commission developed renewable energy in respect of wind, biomass, solar and small hydropower Feed-in-Tariff (REFITS) that were included in the Multi Year Tariff Order (MYTO) II in January 2012. The regulation was approved by government in February 2016 and supersedes the MYTOII [25].

Section 3 of the REFIT states the objectives to include; boost power supply in the country, enhance the attainment of the national targets on renewable energy sourced electricity, encourage greater private sector participation in power generation from renewable technologies by providing investment security and market stability for investors, to develop, promote and harness the renewable energy resources of the country and incorporate all viable ones into the national energy mix and establish a guaranteed price for electricity generated from renewable energy for a fixed period that provides a stable income stream and an adequate return on investment as well as provide priority access to the grid for renewable energy based electricity.

The main features of the REFIT include guaranteed price and access to grid, feed in tariff for solar, wind, biomass and small hydropower plants, power purchase agreement based on plant life cycle of 20 years and electricity distribution companies are to procure a minimum of $1000 \mathrm{MW}$ i.e. $50 \%$ of the total projected renewable sourced electricity while the remaining $50 \%$ is to be sourced from the Nigerian Bulk Electricity Trading Company (NBET) [26].

The Regulations further provide a distinction between small and large generation plants while electricity procured from small plants ranging from $1 \mathrm{MW}$ TO $30 \mathrm{MW}$ will automatically be integrated as renewable energy. In respect of the large plants, the NERC will initiate a competitive bid process where generation is more than $30 \mathrm{MW}$ [26].

In view of the above direction, the respective Discos have been alloted specific renewable energy sources which ensures a balanced energy mix for instance, Ikeja, Ibadan and Eko Discos were assigned $26 \mathrm{MW}, 22 \mathrm{MW}$ and $19 \mathrm{MW}$ of biomass while Abuja Disco was allotted with highest wind sourced-electricity (14.4 MW) and Kaduna and Kano Discos were each allotted $12 \mathrm{MW}$ of solar-source electricity, $10 \mathrm{Mw}$ of small hydro power and $6 \mathrm{MW}$ of biomass [27].

To further encourage investors, NERC has declared that investors who are involved in renewable energy plants would be given an operating period of 20 years within which they would be able to recover their investments for the entire lifespan of the plants.

\section{National Renewable Energy and Energy Efficiency Policy (NREEEP) 2015 [27]}

The National Renewable Energy Efficiency Policy draws its root from the National Energy Policy (NEP). The major difference between the two is that the NREEEP focuses mainly on renewable energy while the NEP deals with both 
fossil fuels and renewable energy sources. The Policy arose as a result of the need for a separate national policy document that provides specifically for renewable energy and energy efficiency. The policy recognises the fact that fuel substitution is important to reduce the negative effects of the use of fuels on the environment and states that the substitution of wood-fuel for instance would reduce deforestation in Nigeria.

The NREEEP's objectives are namely: to enhance energy security in the nation through diversifying the energy supply mix, increase energy access especially in the rural and semi-urban areas, facilitate employment creation and employment and to protect the environment and mitigate climate change and also cover the exploitation and utilization of all renewable energy sources. Just like the National Energy Policy, goals have been subdivided into short term, medium and long term measures and specific timelines attached to them; short term 2013-2015 of achieving (2438 MW), medium term 2016-2020 (8188.2 MW) and long term 2021-2030 (23,134.8 MW) [13]. One of its short term measures for consideration is to strengthen institutional and legal framework for the promotion of energy efficiency and conservation. It is noteworthy to state that the year 2015 has ended and no legislation has been enacted to help fast track the development of renewable energy.

Incentives are also provided in chapter five by way of financial and fiscal incentives. Financial in terms of subsidies, grants which are targeted towards demand size and fiscal incentives which includes tax relief duty, levy waivers targeted at the supply side which is intended to encourage both the demand and supply chain and feed-in-tariffs, establishment of a net metering framework and establishment of a Public Benefits Fund through which a percentage of the tariff is devoted to supporting renewable power generation projects [28]. All this provisions are geared towards ensuring the rapid development of renewable energy and energy efficiency.

In concluding, the NREEEP recognises the need for a conscious effort by government to include renewable energy into the nation's energy mix and states the need for legislative and regulatory structures to be put in place.

The need for stability in the energy sector in Nigeria has led to certain reforms in the energy sector. Over the years, focus was basically on the electric power sector and the first among this was the Electricity Act, the National Power Authority (NEPA) Act, Electricity (Amendment) Act and the National Power Authority (Amendment) Act. Presently, the Electricity Power Sector Reform Act [29] is the principal legislation that regulates the power sector in Nigeria having abrogated the National Electric Power Authority. It is submitted that thus far only policies exist in respect of renewable energy without a legislation put in place to harmonise these policies. This has hindered the rapid development of renewable energy in Nigeria.

\section{National Renewable Energy Action Plan (NREAP) 2016 [30]}

The National Renewable Energy Action Plan is a creation of the Federal Gov- 
ernment, which was drawn in line with the targets set by ECOWAS Renewable Energy Policy (EREP) for 2020 and 2030. NREAP shows government's commitment to drawing strategies with the aim of implementing the objectives of NREEEP. The action plan provides a detailed roadmap of how Nigeria expects to reach its targets for development of the renewable development sector which covers a period of fifteen years from 2015 to 2030 [30].

A summary of NREAP shows the intention of government to achieve an electricity vision of attaining 30,000 MW of power by the year 2030 with at least $30 \%$ renewable energy in the electricity mix (electricity vision 30:30:30) which would be vigorously pursued in a three pronged stage of attaining the stable, then the sustainable and the uninterruptible power supply in Nigeria. The NREAP recognises the importance of renewable energy and states that exploiting available renewable resources will make a strong contribution to the country's energy needs and allow it to be less reliant on conventional internationally traded energy resources.

In meeting with Nigeria's 2020 and 2030, NREAP provides details on sets of measures and plans to enable NREEEP achieve $16 \%$ of renewable targets by 2030.

\section{Assessment of the Success of the Various Renewable Energy Policies}

An examination of the above discussed policies portray a lot of promises and hopes for the country as provisions contained in the policies are laudable and would go a long way in revitalising the energy sector. Despite the various policies, power generation according to Nigeria's Minister of Power, Works and Housing, Babatunde Fashola is abysmal as he stated that as in July 2016, the total installed power generation capacity was $12,522 \mathrm{MW}$; $85 \%$ of which is gas-fired and $15 \%$ is hydro-generated [31]. This figure shows a greater dependence is on fossil fuel while a minimal percentage is on hydropower and not on other renewable energy like solar and wind power. Another key issue that has made renewable energy to be at its nascent stage is the fact that there has been a major focus on the development of conventional traditional energy which has been discovered to be unable to meet the energy needs of the country, thus the need for renewable energy. It is reported that the Hon. Minister Babatunde Fashola revealed that the United Kingdom and the United States of America have at least $25 \%$ coal, $30 \%$ gas, $20 \%$ nuclear and $20 \%$ renewable energy which all make up their energy mix and this has enabled them to adequately cater for their energy needs [32]. This is not the case in Nigeria, were energy consumption and utilisation is majorly from fossil fuel.

To further encourage investments in the renewable power segment, the Renewable Energy Research and Development division of the NERC have developed the renewable energy Feed-in-Tariff (REFITS) that are included in the Multi Year Tariff Order (MYTO) II issued in January 2012 [33]. The Federal 
Government has set a $10 \%$ target for renewable energy usage until 2017 while a $20 \%$ target has been set for the year 2020. The Feed in Tariff is a policy that has worked well in developed countries in Europe. Goals should be set arising from these policies so that it takes costs into consideration without causing deficit in the energy sector particularly the renewable sector [13]. In terms of assessment, it will not be difficult to state that the $10 \%$ target has not been met rather focus will be on the target set for the year 2020 .

It is noted that despite these elaborate plans, programmes and policies, the penetration of renewable energy is still very low. It is noted that though the policy documents contain laudable policies, many are merely produced and never implemented. These documents are also numerous and are characterised by obvious overlaps and conflicts [7]. An instance is seen in the various short term, medium term and long term targets set out in some of the policies which is attributed to as ambitious as some are simply unrealistic especially as the set year has caught up with the targets and have not been met. The multiplicity of the policy documents if not properly harmonised is capable of creating confusion as there would conflict as to which bodies or parties are to handle roles and responsibilities.

There also appears to be gaps in terms of the fact that follow ups of these policies are lacking and this is linked to the fact that there appears to be no unifying umbrella under which all the policies could be effectively managed and implemented [13]. Some of the policies need to be revised for instance, the EPSRA 2005. This is to enable them to be relevant to present day challenges and development in the energy sector. Alignment of these policies and programmes is also imperative as achieving adequate energy supply where renewable energy will be harnessed to play a major role is important and this therefore necessitates the need for the enactment of renewable law where clear rules, roles and responsibilities of various stakeholders would be clearly spelt out. It is submitted that the lack of a proper legislation has contributed to the low interest shown by investors.

There however appears to be a challenge in the sense that the numerous and overlapping policies tend to weaken implementation and hamper focus and there is therefore the need for a legislation to cater for renewable energy. One of the problems is the fact that policies are not sufficient enough to drive renewable energy through as laws form important tools to establish the bedrock of its policies and objectives and the spring-board from which to co-ordinate implementations [34].

Another issue has to do with the fact that installation cost of renewable energy is quite high and as such is out of reach of the poor. In Nigeria, the investment and financing framework is weak in Nigeria [13], however investments in renewable energy can fast track development in this area and legislation can effectively achieve this as investors particularly the private investors will have confidence in investing. 
For now, Nigeria's renewable energy policies seems lopsided as they are a mere repetition of one another thus making the implementation a major challenge as both the leadership in government and the citizens have devised means of boycotting the system [35]. It is therefore important that there should be a conscious effort to put in place a sound legal framework that would bring together a robust legislation just like Ghana, and Germany have done to get renewable energy generation on a firm footing.

\section{Recommendations}

As a result of the various issues outlined above, the following recommendations are suggested:

1) That a renewable energy law be urgently enacted to give efficacy to the policies in order that implementation of these policies would be faster;

2) That the enactment of a legislation would create a dedicated source of funding to be made solely for renewable energy as this will help in subsidising the high cost of materials used in the development of renewable energy in Nigeria;

3) The enactment of a renewable law would help to streamline the various policies into a singular document that would prevent confusion in implementation;

4) That the legislation should provide compliance mechanisms that will ensure enforcements;

5) That an agency be created solely for the development of renewable energy that will effectively utilise the existing policies to achieve a faster and wider spread to include the rural areas.

\section{Conclusion}

It is noted that there has been a proliferation of several renewable energy policies and guidelines that lack legislative flavour. The lack of effective legislation on renewable energy has hindered the implementation and efficient utilization of renewable energy that is considered environmentally friendly. It is recommended that these documents should be harmonised into a legal framework to regulate renewable energy development and utilisation in Nigeria. If the policies discussed above are enacted into law, they transform the energy sector in Nigeria. The approval of the Federal Executive Council and a follow-up enactment renewable energy law to enhance the growth of the renewable energy sector will go a long way to show government's commitment and political will to develop the renewable energy. If Nigeria is to be one of the top twenty nations by 2030 in terms of energy efficiency subsector. This would attract foreign direct investments in the sector. It is submitted that a good foundation has been made in terms of policies and strategies but the lack of a structured support mechanism in terms of a proper legislation for renewable energy poses a significant challenge to the growth and development and utilization of renewable energy in $\mathrm{Ni}$ geria. However, there is need for legislation to be put in place to help galvanise 
and increase the proportion of renewable energy in the overall energy mix of the country.

\section{Conflicts of Interest}

The authors declare no conflicts of interest regarding the publication of this paper.

\section{References}

[1] Musa, S., Idris, D.A., Ibrahim, A. and Jibril, M.T. (2014) Power and Energy Law in Nigeria: The Journey So Far. The Annual Conference of the Nigerian Association of Law Teachers, Abakaliki, 2-6 June 2014, 19ss.

[2] See the Petroleum Act, CAPC10, Laws of the Federation of Nigeria 2010, Oil in Navigable Waters Act, CAPP10, Laws of the Federation of Nigeria 2010, Association Gas Re-injection ActCAPA25, Laws of the Federation of Nigeria, 2010.

[3] Oniemola, P.K. (2015) Powering Nigeria through Renewable Electricity Investments: Legal Framework for Progressive Realization. Journal of Sustainable Development Law and Policy, 6, 84. https://doi.org/10.4314/jsdlp.v6i1.4

[4] Bradbook, A.J. (2018) Achieving Access to Modern Energy Services. In: Omorogbe, Y. and Ordor, A.O., Eds., Ending Africa's Energy Deficit and the Law. Achieving Sustainable Energy for All in Africa, Oxford University Press, Oxford, 26.

[5] National Energy Policy 2003.

https://www.iea.org/policies/5878-national-energy-policy-2003

[6] Nigerian Electricity Hub. The Future of Renewable Energy in Nigeria. http://wwww.nigeriaelectricityhub.com/2015/11/06/the-future-of-renewable-energy -in-nigeria

[7] Emodi, N.V. and Ebele, N.E. (2017) Policies Enhancing Renewable Energy Development and Implications for Nigeria. http://www.pubs.sciepub.com/rse/4/1/2/

[8] GIZ (2015) The Nigerian Energy Sector: An Overview with a Special Emphasis on Renewable Energy, Energy Efficiency and Rural Electrification. https://www.giz.de/en/downloads/giz2015-en-nigerian-energy-sector.pdf

[9] Ajibade, A.A. (2017) The Case for a Coherent Legal Framework for Renewable Energy in Nigeria. 1BUALJ116.

[10] Yamusa II, S.U. and Ansari, H.A. (2015) Renewable Energy Development as a Solution to Rural Electrification in Nigeria. Journal of Business Law and Ethics, 3, 88-89. https://doi.org/10.15640/jble.v3n1a5

[11] National Economic Empowerment and Development Strategy 2004. http://www.cbn.gov.ng/out/publications/communique/guidelines/rd/2004/needs.pdf

[12] Electric Power Sector Reform Act, 2005.

http://www.nigerian-electricityhub-com/download/electric-power-sector-reform-ac t-2005/ (Hereinafter referred to as EPSRA)

[13] Ogunleye, E.C. (2017) Political Economy of Nigerian Power Sector Reform. https://www.wider.unu.edu

[14] Renewable Electricity Policy Guidelines (2006). http://www.iceednigeria.org/backup/workspace/uploads/dec-2006.pdf

[15] Onyi-Ogelle, H.O. (2016) The Implications of Legal Reforms in the Nigeria Power Sector. African Research Review, 10, 283-285.

https://doi.org/10.4314/afrrev.v10i3.18 
[16] Renewable Electricity Action Programme. http://www.iceednigeria.org/backup/workspace/uploads/dec-2006-2.pdf

[17] GIZ (2015) The Nigerian Energy Sector: An Overview with a Special Emphasis on Renewable Energy, Energy Efficiency and Rural Electrification. http://www.giz.de/en/downloads/giz2015-en-nigerian-energy-sector.pdf

[18] National Biofuel and Incentives 2007. http://www.community.irena.org/rbsvc25562/attachments/rbsv25562/News/97/2/N ationalBiofuelsPolicy.pdf

[19] Nigeria Vision 20: 2020. https://www.nationalplanningcycles./org/sites/default/files/planning cycle reposito ry/nigeria vision-20-20-20.pdf

[20] Nigeria Vision 20: 2020. http://www.nationalplanning.gov.ng/index.php/national-plans/nv20-2020

[21] National Energy Master Plan. https://www.iceednigeria.org/backup/workspace/uploads/nov-2005.pdf

[22] Renewable Energy Feed in Tariff, 2016. https://www.iea.org/policiesandmeasures/pams/nigeria/name-154529-en.php

[23] Nigerian Electricity Regulatory Commission. Electricity Tariff in Nigerian Supply Industry. http://www.nercng.org/index.php/home/myto

[24] International Energy Agency. Nigeria Feed in Tariff Regulations 2015. https://www.iea.org/media/pams/nigeria NIGERIA FIT regulation2015

[25] See Sections 5and 8 of the Regulation. Nigerian Electricity Regulatory Commission, Renewable Energy Feed in Tariff. http://www.nercng.org/index.php/home/operators/renewableenergy

[26] Africa-EU Renewable Energy Cooperation Programme (2020) Nigeria: Africa-EU Renewable Energy Cooperation Programme (RECP) Strategy 2020.

https://www.icafrica.org/en/knowledge-hub/article/africa-eu-renewable-energy-coope ration-programme-recp-strategy-2020-242/

[27] National Renewable Energy Efficiency Policy 2015. http://www.power.gov.ng/download/NREEEPOLICY2015-FECapprovedcopy.pdf

[28] National Renewable Energy Action Plan, 2016. Federal Ministry of Power, Works and Housing, National Renewable Energy Action Plan (NREAP) 2015-2030 (2016). http://www.pwh.gov.ng/.../NATIONALRENEWABLEENERGYACTIONPLANS.(N REAP).PDF

[29] Offgrid Nigeria (2017) Nigeria: 5 Months Behind on Renewable Energy Action Plan.

http://www.offgridnigeria.com/nigeria-5-months-behind-on-renewable-energy-acti on-plan

[30] Detail Commercial Solicitors. Prospects of Solar Power in Diversifying Nigeria's Energy Mix.

http://www.financialnigeria:com/prospects-solar-power-in-diversifying-nigeria-s-e nergymix-feature.67.html

[31] CSRFILES Digest (2017) Power Nigeria: The Role of Government in The Energy Mix. Guardian, Lagos, 32.

[32] Banwo \& Ighodalo. A Succint Guide to Investing in Nigeria's Renewable Energy.

[33] Mas'ud, A.A., Wirba, A., Ardila-Rey, J.A., et al. (2017) Wind Power Potentials in Cameroon and Nigeria: Lessons from South Africa. Energies, 10, 443.

http://www.mdpi.com/journal/energies 
[34] Ehiemua, R.O. (2013) Renewable Energy Management Dilemma in Nigeria: Its Environmental Impact and the Inadequacies of Laws. Natural Resources and Environmental Law Journal, 5, 77.

[35] Aliyu, A.S. (2015) Current Status and Future Prospects of Renewable Energy in Nigeria. Renewable and Sustainable Energy Reviews, 48, 336-346.

https://doi.org/10.1016/j.rser.2015.03.098 